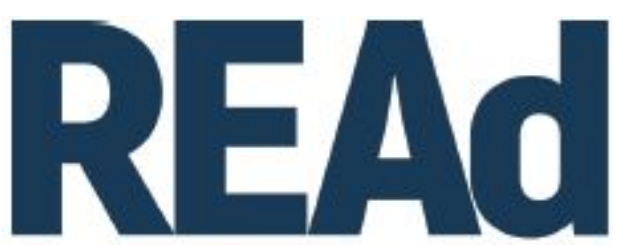

Revista Eletrônica de Administração

\title{
DESAFIOS À PRODUÇÃO DE CONHECIMENTO EM ADMINISTRAÇÃO EM TEMPOS DE CRISE
}

\author{
Guilherme Dornelas Camara ${ }^{1}$
}

$\underline{\text { http://dx.doi.org/15.1590/1413-2311.328.116970 }}$

Quando assumi a tarefa de Editor-chefe da REAd - Revista Eletrônica de Administração, em setembro de 2019, estava ciente de que teria muitos desafios pela frente. No entanto, nem um pesadelo tenebroso, imaginava realizar essa tarefa em meio a uma crise de tamanha proporção, decorrente da pandemia que assolou todo o mundo e que afetou, especialmente, o nosso país. No momento em que escrevo essas linhas, último terço de julho de 2021, mais de 543 mil vidas já foram perdidas para o SARSCov-2 no Brasil (CONASS, 2021).

Além do luto de centenas de milhares de famílias, são sinais da crise os números de famílias que enfrentam a fome (mais de 19 milhões de pessoas) e vivem na pobreza (mais de 14,5 milhões de famílias vivem abaixo da linha de miséria, ou seja, com menos de 1 dólar PPC/dia) (REDE PESSAN, 2021) - fatos que se somam ao aumento contínuo da cesta básica e a níveis alarmantes de desemprego (14,8\% da PEA) e desalento $(5,952$ milhões de pessoas) (IBGE, 2021). Os indícios são de que não estamos a enfrentar apenas mais uma simples crise, que assola o Brasil de tempos em tempos, mas que, de fato, vivemos uma crise estrutural (MESZÁROS, 2009), que coloca em questão a viabilidade do nosso modo de vida enquanto sistema reprodutivo social.

No contexto acadêmico, as atividades de ensino, pesquisa e extensão também foram alteradas pela pandemia. $\mathrm{O}$ ensino remoto emergencial tornou-se uma estratégia para tentar dar alguma continuidade à relação de educação, o teletrabalho realizado no ambiente doméstico invadiu a vida de docentes, estudantes e, também, de

1 Universidade Federal do Rio Grande do Sul - Escola de Administração; Porto Alegre - RS (Brasil); http://orcid.org/0000-0001-5021-9535; guilherme.dornelas@ufrgs.br 
pesquisadores. Frente a tudo isso, produzir conhecimento em uma área das ciências sociais aplicadas, como é a Administração, foi um verdadeiro desafio.

Em 2020 e no primeiro semestre de 2021, a REAd recebeu 651 submissões de artigos inéditos. Como estratégia para evitar que a crise que assola a todo o país afetasse o fluxo de submissões à REAd, foi criada, em 2020, a chamada especial "contribuições da administração para superar a crise em tempos de pandemia", que continua recebendo trabalhos em fluxo contínuo.

Nesse período, a REAd ampliou a divulgação de trabalhos estrangeiros, em inglês e espanhol, reforçando a inserção da Revista no cenário internacional, especialmente em Nuestra América. Uma iniciativa que deve reforçar ainda mais isso é a chamada de trabalhos para um número especial "Contribuições do Pensamento Social Latino-Americano para a produção de conhecimento, a prática e o ensino em Administração e Estudos Organizacionais”, organizada por Paulo Emílio Mattos Martins, Paulo Ricardo Zílio Abdala e Kléver Efraín Naranjo. As submissões para esta chamada estão abertas até 30 de setembro.

Não poderia deixar de prestar meu agradecimento público às e aos avaliadores da REAd, que mesmo em um contexto tão adverso, se comprometeram em manter a qualidade dos pareceres elaborados. Seu trabalho é motivo de qualificação da REAd. Ainda, e não menos importante, menciono o trabalho das bolsistas que me auxiliaram na revisão dos textos e cujo trabalho é elogiado por autores: Malu Fernandes e Débora Destefani.

A seguir, apresento os textos que compõem esse número, que encerra meus dois anos à frente da REAd. Foi um grande e satisfatório desafio. Desejo um excelente trabalho ao próximo Editor ou Editora-chefe, quem conheceremos em breve.

O texto que abre esse número é Globalização, (de)colonialidade e (contra)hegemonia no contexto da internacionalização da educação superior: o grito surdo da academia, de Mário César Barreto Moraes e Fernanda Geremias Leal, quem propõem uma análise crítica e reflexiva do fenômeno da internacionalização da educação superior, a partir de conceitos estruturantes associados à globalização, (contra)hegemonia e (de)colonialidade.

Em Produtivismo acadêmico e suas consequências para a produção científica na área de Administração, Ely Severiano Junior, Diego de Oliveira da Cunha, Deborah Moraes Zouain e Clayton Pereira Gonçalves identificam como o grau de imersão 
em processos sociais de influência pode aumentar o produtivismo acadêmico em pesquisadores da área de Administração.

O terceiro texto desse número é Vida universitária nos cursos de Administração: jogos vorazes ou os melhores anos de nossas vidas?, de Hélio Arthur Reis Irigaray, Alessandro Vendramini Langerhorst e Daniel Adorno. Nele, por meio de uma pesquisa de cunho etnográfico, os autores apreendem como as diferentes identidades dos alunos dos cursos de graduação em Administração são reconhecidas em suas interações sociais.

Um recurso metodológico que se tornou muito comum durante a pandemia foi a revisão sistemática, que já compete em número com as submissões de estudos de caso para a REAd. Suélem Viana Macedo e Josiel Lopes Valadares realizaram uma revisão sistemática d'Aprodução acadêmica brasileira sobre corrupção, cujo objetivo é caracterizar a pesquisa acadêmica brasileira sobre corrupção, produzida pelos campos das ciências humanas e das ciências sociais aplicadas.

O artigo Métodos biográficos para a pesquisa em Administração: princípios, potencialidades, práticas e desafios, de Fabiana Pimentel Santos e Eduardo Paes Barreto Davel traz as potencialidades desses métodos para a Administração, integrando contribuições de vários campos disciplinares para sistematizar conhecimentos acerca dos princípios, potencialidades, práticas e desafios dos métodos biográficos.

No sexto trabalho, Análise ergológica da trajetória de vida de um sindicalista, Kleyton Teixeira Valadão e Mônica de Fátima Bianco trazem a história de vida de um sindicalista, diretor de um sindicato de vigilância privada.

Karine Francisconi Chaerki e Queila Regina Souza Matitz abordam a Organização como evento: implicações conceituais e teóricas da adoção de uma ontologia processual strong-view, em um texto que discute implicações da adoção de uma noção de evento de base ontológica processual strong-view no campo de estudos organizacionais.

Já no oitavo artigo, Deise Luiza da Silva Ferraz, David Silva Franco e Jéssica Alves Maciel estão Desvelando o prosumption: o produtor-consumidor, as plataformas digitais e o movimento do capital, expondo como as atividades do consumidor-produtor se integram à dinâmica da acumulação capitalista.

Em Subprocessos de engajamento em culturas de consumo de cervejas artesanais, João Menezes Filho, Minelle Enéas da Silva e Brunno Fernandes Silva 
Gaião identificam as categorias que suportam a existência de um efetivo engajamento em relação à cognição, à emoção e ao comportamento dos consumidores da bebida.

Influence factors of culture of intelligence in organizations é o texto de Vivian Aguiar de Souza e Raquel Janissek-Muniz em que identificam os fatores da cultura organizacional que podem influenciar os processos de inteligência nas organizações; seguido da Análise de uma base de dados inédita sobre a formação acadêmica dos dirigentes das instituições financeiras brasileiras, de Marcelo Pinho, Lucas Oishi Grigolin, João Vitor Carvalho Lopes, na qual os autores analisam a formação acadêmica de dirigentes de instituições financeiras brasileiras.

Por fim, em Além das equipes intergeracionais: possibilidades de estudos sobre ageismo, Thales Fabrício da Costa e Silva, Débora Bruna Alves Almeida, Eduardo de Camargo Oliva e Edson Keyso de Miranda Kubo elaboram um ensaio teórico sobre as principais estratégias de enfrentamento no contexto organizacional, refletindo criticamente sobre a prevalência que é dada à formação de equipes intergeracionais nas organizações.

Boa leitura!

\section{REFERÊNCIAS}

CONASS. Conselho Nacional de Secretários de Saúde. Painel CONASS Covid-19. 20 jul. 2021. Disponível em: https://www.conass.org.br/painelconasscovid19/. Acesso em 20 jul. 2021.

IBGE. Instituto Brasileiro de Geografia e Estatística. PNAD Continua: Pesquisa Amostral por Amostra de Domicílios. $1^{\mathrm{o}}$ trimestre de 2021. Disponível em: $<$ https://www.ibge.gov.br/estatisticas/sociais/populacao/9173-pesquisa-nacional-poramostra-de-domicilios-continua-trimestral.html?t=destaques $>$. Acesso em 13 jun. 2021. MÉSZAROS, Istvan. Para além do capital: rumo a uma teoria da transição. São Paulo: Boitempo, 2009.

REDE PENSSAN. Rede Brasileira de Pesquisa em Soberania e Segurança Alimentar. Inquérito nacional sobre insegurança alimentar no contexto da pandemia da Covid-19 no Brasil. 2021. Disponível em: http://olheparaafome.com.br/VIGISAN_Inseguranca_alimentar.pdf. Acesso em 13 jun. 2021. 